\title{
ESCREVER A DIFERENÇA - O EXOTISMO SEGUNDO CÉSAR AIRA
}

WRITING THE DIFFERENCE - EXOTICISM ACCORDING TO CÉSAR AIRA

Karl Erik Schøllhammer

ORCID 0000-0001-9259-1933

\section{Pontifícia Universidade Católica do Rio de Janeiro} Rio de Janeiro, RJ, Brasil

\section{Resumo}

O ensaio discute os conceitos de exótico e de exotismo na obra de César Aira como chave para compreender o fazer literário e o consequente engendramento da capacidade de fabulação e de criação de mundos possíveis entre realidade e imaginação.

Palavras-chave: exótico; literatura de viagem; estética da diversidade.

\begin{abstract}
The essay discusses the concept of the exotic and exoticism in the work of César Aira as a key to understanding literary creation and the subsequent generation of the capacity for fabulation and creation of possible worlds between reality and imagination.
\end{abstract}

Keywords: exotic; travel literature; esthetics of diversity.

\section{Resumen}

El ensayo discute los conceptos de exótico y de exotismo en la obra de César Aira como clave para comprender la obra literaria y la consecuente generación de la capacidad de fabulación y creación de mundos posibles entre la realidad y la imaginación.

Palabras clave: exótico; literatura de viajes; estética de la diversidad.

El hormigueo de la calle, su frondosidad creadora, le procuran diariamente un espectáculo continuo, variado y gratuito. En la Rue d'Aboukir o la Place du Caire, como en la Porte de Clignancourt o la Goutte d'Or, saborea la presencia fluida e incesante del gentio, su movilidad desordenada, su diáspora febril por la rosa de los vientos. La paulatina deseuropeización de la ciudad -la emergencia de zocos y hammams, venta ambulante de totems y collares, pintadas en árabe y turco-le colma de regocijo. La complejidad del ámbito urbano ese territorio denso y cambiante, irreductible a la lógica y programación - invita a cada paso a trayectos versátiles, que tejen y destejen, lienzo de Penélope, una misteriosa lección de topografía. Los modestos ilotas de la difunta expansión 
económica han traido con ellos los elementos e ingredientes necesarios a la irreversible contaminación de la urbe: aromas, colores, gestos, un halo de amenazadora proximidad. Nuestro excéntrico personaje ha advertido que no es necesario coger el avión de Estambul o Marraquech en busca de exotismo: basta con salir a estirar las piernas para topar inevitablemente con él. Juan Goytisolo, 1998, p. 123

“... por acaso o futuro da literatura, de toda a literatura, não estará no exotismo." César Aira, 1991, p. 265

"El americano no necesita viajar tanto como el europeo; en sus países inconexos, a medio hacer, encuentra mitades exóticas mirando por la ventana." César Aira, 1993, p. 78

Entender a dinâmica da escrita do autor argentino César Aira é um desafio com muitas respostas. Existe um projeto literário por trás dessa enorme variedade de textos produzidos pelo autor que ainda não foi revelado. Mesmo assim, parece que a variedade em si possui um valor, o que se expressa no movimento expansivo e espiralado de narraçóes que se desdobram propulsionadas por desvios mínimos. Por trás da capacidade fabulatória de Aira e de sua prospecçáo de mundos possíveis parece haver um pequeno movimento aleatório lateral que preserva um grau mínimo de diversidade e de estranheza.

$\mathrm{Na}$ reflexão que se segue, debateremos como o conceito de "exotismo" aparece, em alguns textos de Aira, ligado a esse coeficiente necessário de estranheza. A etimologia indica a raiz grega exo da palavra, que significa "de fora". Exóticas eram as mercadorias trazidas para a Europa pela empreitada colonial do Oriente ou das Américas. O significado podia equivaler a "estrangeiro", mas nem tudo que era estrangeiro necessariamente era exótico. Havia uma associação na palavra ao estrangeiro trazido para a cultura Ocidental, para o seio do "familiar", em que a sensação "exótica", no século 18, ganhava um sentido mais amplo de estranhamento e mistério. Nesse período, o exotismo indicava a representaçáo das culturas distantes e às vezes um valor agregado às mercadorias de uma cultura para o consumo de outra. Dessa maneira, a discussão teórica aborda a questáo do exotismo quase sempre com intenção crítica dirigida ao caráter artificial e exagerado em determinadas representaçóes de países, culturas ou povos distantes. Assim, o uso coloquial do termo tem semelhanças com o "orientalismo", na medida em que indica um enfeite hiperbólico em certas descriçôes dos países não europeus e frequentemente tropicais, exaltando sua ligação com desejos e fantasias recalcados, relacionados à sua alteridade. 
Por outro lado, surge na modernidade e numa perspectiva decolonial uma interpretaçáo positiva do exotismo que valoriza seu potencial crítico diante da alienação de um capitalismo expansionista. É nessa ambiguidade que a contribuição de Aira se insere e em que se elabora sua relação com - e sua relevância para - a literatura. O escritor dedica dois ensaios à questão, um de 1991 e outro de 1993. Começamos com o segundo deles, "O exotismo" (AIRA, 1993, p. 73-79), o mais elaborado em relação ao tema. Cesar Aira descreve aí, historicamente, o desenvolvimento do conceito e distingue três fases da modernidade. A primeira refere-se ao classicismo francês do século 18, com o exemplo notável do livro Cartas persas, de Montesquieu, de 1721. Nessa ficção epistolar, os protagonistas centrais são dois viajantes persas que chegam a Paris: Rica e Usbek.

Destinadas a quem ficou na Pérsia ou na Turquia, as cartas dos dois viajantes descrevem a capital francesa com o olhar do outro, do estrangeiro que normalmente era objeto do olhar colonial. Essa inversáo abre o olhar do leitor pelo estranhamento diante da visáo do outro. Segundo Aira, se sustenta no dispositivo ficcional do "como se", e descerra ao mesmo tempo as portas para as ciências sociais, principalmente a etnografia e a antropologia, possibilitando simultaneamente o nascimento do romance moderno. Aira situa na fase clássica o descobrimento do que vai chamar "la ficción como auxiliar del pensamento" (AIRA, 1993, p. 74), ${ }^{1}$ o que amarra o lado científico ao lado romanesco da modernidade de maneira decisiva. No segundo momento, a literatura descobre a viagem como dispositivo de criação imaginária, e agora já não é mais o persa que descreve sua aventura em Paris, mas o viajante francês que traz sua experiência da visita à Pérsia, como Gustave Flaubert em Voyage en Égypte, de 1851. Para o viajante europeu, os países distantes e sua cultura exótica oferecem um objét trouvé para a imaginaçáo literária, um dispositivo para a criatividade que permita uma simbiose de realidade e imaginação só acessível pela ficção.

$\mathrm{Na}$ alta modernidade, no terceiro momento do exotismo do século 20 e do momento contemporâneo, já não é o persa que descreve sua visita a Paris, nem o francês que viaja e relata suas aventuras na Pérsia. Pelo contrário, o protagonista hoje será, segundo Aira, um persa narrando a "verdadeira" Pérsia para os leitores franceses. "Ya no es necessário viajar, ni importar nativos" (AIRA, 1993, p. 75). ${ }^{2} \mathrm{Ou}$, poderíamos acrescentar, o exótico já não é um desafio para a experiência lá fora, ele tornou-se um elemento do cotidiano na globalização e, segundo a proposta de Aira, uma dimensão que hoje se confunde com os "labirintos da nacionalidade", em que o exótico

1 "A ficção como auxiliar do pensamento."

2 "Já nâo é necessário viajar, nem importar nativos." 
expressa um fetiche mercantil permeando a circulação, promoção e venda das mercadorias na esfera global. Para os escritores, que nascem "franceses, persas ou argentinos", a nacionalidade é o acaso que mantém o exotismo e, com ele, sempre o perigo da "má consciência" e do juízo estético de autenticidade ${ }^{3}$ diante do perigo da superficialidade frívola.

Entende-se nesse ponto que a nacionalidade e a língua materna de certa maneira se tornaram os repositórios do exotismo no contemporâneo e, portanto, catalisadores do coeficiente de estranheza necessário para estimular o trabalho da imaginação literária. A banalização das traduções no mercado literário global é contrastada com a intraduzibilidade que aparece revigorada nos detalhes idiomáticos e referências a costumes cotidianos nas tentativas de descriçóes frequentemente fracassadas do ambiente local.

O segundo ensaio Nouvelles impressions du Petit Maroc (2011), escrito por César Aira em 1991, dois anos antes de "O exotismo", durante um período de residência em Paris, foi publicado originalmente em versão bilíngue, e seu uso do francês no título ironicamente cria um efeito de intraduzibilidade do texto. De entrada, o ensaio lança a discussão sobre o que é a língua estrangeira e lembra a conhecida citação de Marcel Proust, de que "todos os livros que amamos parecem escritos numa língua estrangeira". Adotada por Gilles Deleuze, a frase foi convertida apologeticamente num lugar-comum para dizer que escrever literatura é escrever como se fosse numa língua estrangeira. Nada mais apropriado então, em resposta irônica do escritor argentino ao convite da Maison des Écrivains Éstrangers et des Traducteurs, do que versar tanto sobre o que significa, no contemporâneo, ser escritor estrangeiro quanto sobre o desafio da tradução na cultura globalizada - em que a disputa é travada, com muita relevância e atualidade no contexto francês, entre as línguas nacionais e as línguas globais, com ambiçōes de ganhar status de línguas francas. Mas o tema do ensaio de Aira, no fundo, é discutir o que catalisa a escrita literária. Entre os caminhos diversos, ele discorre sobre as coincidências, as guerras e as viagens. O próprio título "Nouvelles impressions" faz assim uma leve alusão ao gênero de relatos de viagem, dos séculos 18 e 19, cujo desenvolvimento se confunde com o do romance dessa época: a aventura da viagem, o descobrimento dos continentes estrangeiros e a exploração do desconhecido e do estrangeiro que desabrocha no auge do exotismo.

É bom lembrar que o próprio romancista, em referência meta-histórica a esse período, estreou em 1981 com o romance Ema, la cautiva, contando a história de viagem de Ema (uma mestiça ou mulata) e seus filhos, de Buenos

3 Aira discute a famosa observaçấo de Jorge Luís Borges de que "no Corão não há camelos" como um exemplo da exigência modernista de "autenticidade", com a qual não concorda. Se a literatura tem por objetivo rever os valores culturais, nem a autenticidade deve ser preservada. Não se deve excluir uma literatura que se propóe a ser inautêntica (1993, p. 75-76). 
Aires para Patagônia no século 19. Ele reelaborou ficcionalmente os relatos das cautivas, as mulheres creollas presas entre os índios, tal como já descritos no clássico La cautiva, de Esteban Echeverría, de 1837, mas aqui repensando e dissolvendo a dicotomia entre civilização e barbárie num complexo tecido de relaçóes entre a jovem República e os povos indígenas em vias de extermínio. Mais tarde, Aira retoma o cenário histórico da conquista do desierto no romance La liebre (1991), em que acompanha a viagem de um naturalista inglês, Clarke, cunhado de Darwin, acompanhado por um guia gaúcho e um aristocrático aquarelista porteño a terras indígenas à procura de um raro animal, a liebre legibreriana. Finalmente, em 2000, César Aira refina o tema dos viajantes em terras argentinas, agora com uma precisáo de pesquisa histórica inédita, com o magnífico romance Un episodio en la vida del pintor viajero (2020), que reconstrói a narração da viagem realizada em 1837 pelo pintor alemão Johan Moritz Rugendas em companhia do jovem discípulo Robert Krause, cruzando as cordilheiras a partir do Chile e descendo pelo vazio misterioso das pampas. Um dos objetivos dessa viagem de Rugendas era perseguir alguns cenários extremos para a vasta experiência do pintor viajante e suas técnicas pictóricas; por exemplo, atravessar o imenso vazio das pampas, que o levará praticamente à morte, atingido em cheio por um raio, com nefastas consequências físicas para seu corpo. Ainda em processo de recuperação o pintor vivencia afinal o desejado ataque de uma tribo indígena cujo testemunho desafia todas as técnicas na descrição desse evento exótico e incompreensível.

Nos três exemplos de narrativas históricas acerca da Argentina do século 19, o exótico está presente como tema central e mostra que, nas Américas, o viajante convive com a estranheza e precisa olhar apenas para a realidade própria. Como no século 19, assim também hoje: "A ese otro país dentro del suyo se le puede dar signo negativo (la barbarie, como en Euclides o en Sarmiento) o positivo (la selva edénica de $O$ Guarani). Sea como sea, ese país otro se vuelve 'otro' absoluto, literatura, como la infancia, o el amor" (AIRA, 1993, p. 78). ${ }^{4}$

Aira se propóe a entender a importância de ter uma boa história para contar (2011, p. 142). O que é uma boa história? A resposta surpreendente é que as boas histórias se tecem ou se teceram principalmente em torno das guerras. O problema hoje é que este tema tem sido substituído pelo turismo. Os períodos de paz e prosperidade não fornecem material narrativo suficiente, e o simulacro da impermanência agora é a viagem, que no século 20 se confunde com o turismo - e isso pode explicar a crise da narrativa contemporânea, com

4 "Pode-se atribuir a esse outro país dentro do seu país um sinal negativo (a barbárie, como em Euclides ou Sarmiento) ou positivo (a selva edênica de O Guarani). Seja como for, esse outro país se torna 'outro' absoluto, literatura, como a infância e o amor." 
algumas poucas exceçóes; por exemplo, os de escritores e viajantes notáveis como Bruce Chatwin. De qualquer forma, a viagem e o turismo são uma das diferentes maneiras de observar contingências aparentemente insignificantes ou provocar pequenos incidentes que podem servir de ponto de partida para grandes causas. "O escritor faz um universal mítico do individual irrepetível, mediante uma história; não há outro modo de fazê-lo, pois o que não é relato está condenado às cinzas de uma generalização de sentido comum" (ibid.).

Inevitavelmente, ao falar de relatos de viagem, o ensaio também toca no assunto do exotismo, e o pretexto é a leitura de René Leys, romance do escritor francês Victor Segalen (1878-1919): "me fez pensar se por acaso o futuro da literatura, de toda a literatura, não estará no exotismo. Não é a única coisa que este livro maravilhoso me fez pensar; diante de um triunfo tão completo, é inevitável perguntar como foi possível, como o autor conseguiu?" (AIRA, 1991, p. 265). Este triunfo consiste, segundo Aira, em "viver a realidade da fábula. O real da fábula é o próprio coração do que chamamos literatura, e não é tão paradoxal quanto parece porque é aí onde nasce o que chamamos paradoxo". Curiosamente, ele coloca esse mérito do romance de Segalen em contraste direto com sua própria chinoiserie, seu romance chinês Una novela china, de 1987, em que a realidade da fábula criou um fracasso ali onde Segalen logrou seu triunfo. Não fica claro por que Aira caracteriza seu próprio romance de "fracasso". Una novela china é a história do Lu Hsin, que vive na China durante a contraditória época da Revolução Cultural, período em que a história cultural é questionada, e o passado, colocado em xeque. A reconstruçáo desse cenário oriental torna-se o panorama de fundo para uma história de amor entre Lu e uma montanhesa que ele encontra ainda criança e resolve amar e educar para virar sua mulher.

Comparando o romance de Aira com René Leys, podemos traçar algumas pistas. Sem dúvida o romance de Segalen foi seu maior legado literário. Escrito em 1911, foi publicado apenas em 1922, depois da morte acidental do escritor em 1919, e é considerado a forma literária que ele encontrou para concluir seu ensaio sobre o exótico. Isto é, como alternativa ficcional e experimental ao ensaio teórico e programático, o narrador, chamado "Segalen" (sic!), escreve um diário ficcional sobre sua viagem acompanhado pelo jovem belga René Leys, seu professor de chinês e totalmente bilíngue, com quem ele se propóe a penetrar na cidade proibida do imperador. A história se desenvolve durante alguns meses de 1911, interrompida por mergulhos numa temporalidade milenar e com um enredo quase policial, em que "Segalen", encantado e talvez apaixonado pelo jovem belga, começa a desconfiar da credibilidade da percepçáo e das palavras de seu acompanhante. Depois de um plano mirabolante de ajudar a imperatriz a fugir do palácio, o jovem Leys finalmente é encontrado morto, envenenado. Uma das possibilidades 
é o suicídio decorrente do fracasso do projeto e talvez do peso das palavras de dúvida do narrador. Outra hipótese é de que teria sido assassinado em consequência das circunstâncias políticas. Assim, a característica principal do romance acaba sendo essa dúvida aberta entre realidade e imaginação, verdade e mentira, ou, como termina o romance, "Sim ou não".

$\mathrm{Na}$ verdade, Segalen deixa muitas dúvidas para estimular o imaginário que para ele é a extensão, a completude do real. É pela imaginação que o conhecimento do mundo pode ser acessado em sua amplitude. Não dá para julgar se a sensação de "fracasso" sentido por Aira ao ler René Leys se refere a esse apagamento da fronteira entre realidade e imaginaçáo. Podemos apenas observar que no romance El mármol, de 2011, o autor lança mão de uma outra estratégia narrativa em que a mística da China imperial ressuscita a partir de uma transaçáo banal de falta de troco num mercadinho chinês em Flores, bairro do autor em Buenos Aires. Aqui, o protagonista, depois de realizar uma compra, recebe uma série de objetos para compensar alguns centavos de troco: primeiro umas pilhas AAA, mas a quantia de dinheiro ainda não está completa, entâo o atendente chinês, que não fala espanhol, insiste, e o narrador escolhe outra coisa: um olho de borracha que emite luz, depois uma tabela de proteínas, em seguida uma fivela dourada e então uma lupa, depois um anel de plástico e uma câmera em miniatura. Essa absurda sequência de chinoiseries globalizadas, materialidade contemporânea do exótico, ganha importância no desdobramento de um complexo enredo fantasioso que envolve viagens em outras dimensóes e encontros com extraterrestres. O exótico já não é mais propriedade da mística do Império chinês milenar, a China está aqui e em todo lugar, e seu segredo oculto talvez esteja num punhado de glóbulos brancos que se parecem com mármore.

Percebe-se na exposição de Aira em relação ao exotismo uma profunda ambiguidade que, até mesmo a respeito da nacionalidade, é repetida numa visão crítica da ideologia nacionalista e da fundaçáo moderna dos Estados nacionais do século 19 , que se reproduz até hoje com consequências políticas desastrosas, em contraponto com a nacionalidade vista como o labirinto em que o autor localiza o miolo do intraduzível.

É possível identificar ambiguidade parecida em Victor Segalen, muito admirado por Aira e que deixou um longo, incompleto e inédito Essai Sur l'Exotisme Une Esthétique du Divers (1978). Segalen ironiza, já em 1908, o traço pitoresco de "palmeiras e caravanas, capacetes coloniais, peles negras e sóis amarelos" (SEGALEN, 2002), que identifica com escritores "pseudoexots" como Pierre Loti (1850-1923) e Lafcádio Hearn (1850-1903). Para Segalen, essa postura remonta a escritores românticos do início do século XIX, como George Sand e Alphonse de Lamartine, que interpretam mal a relação com a natureza como um tipo de alteridade "exótica" que, na 
visão de Segalen, é apenas um corolário deles próprios. A revolta de Segalen contra o exotismo romântico da época era porque ele fechava os olhos para a cumplicidade com a empreitada colonial e identificava o mundo de culturas desconhecidas com o terreno espacial estático explorado, nesse período, pelo competitivo expansionismo geográfico europeu na África e na Ásia. Em vez disso, Segalen se propunha a missão literária de aprofundar a dimensão temporal e histórica, e recriar sua pureza original para assim redescobrir a intensa sensação perdida da diversidade. Nessa perspectiva positiva, Segalen exaltava sua visão particular do exotismo, que considerava uma defesa contra a implacável banalidade da vida cotidiana sob um capitalismo transformado pelo imperialismo colonial. $\mathrm{Na}$ realidade social europeia das primeiras décadas do século 20, Segalen acreditava que o exotismo, como estética da diversidade, poderia trazer resistência de imaginação e poesia. Se as atitudes colonialistas perverteram a capacidade de perceber e apreciar o exótico, uma nova visão estetizante e restauradora deveria substituí-las.

Vamos reencontrar essa dupla visão do exotismo nos ensaios de Aira, para quem Segalen é o verdadeiro ídolo. Aira vai comparar Victor Segalen com seu contemporâneo Pierre Loti, escritor autobiográfico cujas ficçóes se desenvolvem nos ambientes geográficos em que viajou como oficial da marinha durante a vida toda: Taiti, Senegal, Turquia e, principalmente, Japão. Discordando das críticas de Segalen, para quem Loti expressa o exotismo romântico, César Aira recupera a imagem de Pierre Loti e de certa maneira resgata o descritivismo dos romances do escritor francês, por exemplo, em Madame Chrysanthème, de 1887, ambientado no Japão. Para Aira, a estratégia de Loti ante o exótico é exercer os rituais interpretativos sem empreender uma análise das estruturas subjacentes, por exemplo, da sociedade e da cultura japonesas. Comparado com Segalen, diz Aira, Loti parece um "sinólogo" diante de alguém que se tornou "chinês". Acompanhando seu argumento, tornar-se "chinês" seria o caminho do artista.

Mas a comparação entre os dois escritores não se sustenta, pois Segalen na realidade não se propóe to go native, ele mantém a distância e critica exatamente a identificação forte do exotismo romântico com essa ilusão. Além disso, Aira acrescenta por fim, à comparação entre Loti e Segalen, o exemplo do viajante e exotista mais excêntrico de todos, Raymond Roussel, escritor experimental milionário que viajava pelo mundo de navio e escreveu um livro famoso sobre a África - Impressions d'Afrique, de 1910 - sem sair de seu camarote. Basta lembrar a profunda admiração pela literatura de Roussel, a quem Aira dedicou um ensaio seminal em que se lê a seguinte citaçáo de Roussel: "De todas as minhas viagens jamais tirei nada para meus livros" (AIRA, 2018, p. 86). 
Se Roussel então serve de exemplo da criação de uma "literatura pura", capaz de gerar novos mundos sem precisar de inspiração na experiência autobiográfica, Pierre Loti, admirado por Roussel é o escritor para quem "o exótico é o instante da constituiçáo do olhar”, observa Aira (2011, p. 1649), ao comentar suas descrições do Japão, cuja superficialidade generosa renuncia às explicaçôes históricas e socioeconômicas, e acaba criando um estilo exótico de inutilidade inocente.

Em resumo, os dois ensaios de Aira de início distinguem entre um exotismo inocente e romântico, com o exemplo de Pierre Loti - cuja literatura ele inicialmente caracteriza de superficial e frívola -, e o de Victor Segalen - cuja estratégia ele descreve como próxima à ciência, sem se passar por ela. No final, a diferença expressa uma disputa de valores:

La busca de legitimación del artista frente a la ciencia o la filosofía se manifiesta en la afirmación de sus derechos. El derecho a la inautenticidad, por ejemplo, o a la transmutación de los valores en general. La legitimación tiene en vista el puesto del artista en la sociedad. Y precisamente el exotismo se ocupa de posiciones: empieza inventando un individuo único y heterogéneo en una sociedad funcional, $y$, en un mecanismo inverso y complementario, inventa luego una sociedad "artista" (el Japón de Loti, o el de Barthes) en la que lo único heterogéneo es el extrańamiento de la mirada que la expresa (AIRA, 1993. p. 77). ${ }^{5}$

No ensaio "Exotismo", a dicotomia entre os dois exotismos ganha uma terceira posiçẫo representada por Raymond Roussel. Se Segalen luta pela legitimidade morando na China, aprendendo a língua e tornando-se chinês, no caso de Roussel, "Hacerce chino es hacerse escritor" (1993, p. 77), ${ }^{6}$ não pelo caminho da profundidade crítica de Segalen, mas pelo exemplo da superficialidade de Loti. Para o leitor brasileiro, é interessante neste ponto observar os dois exemplos mencionados por Aira para ilustrar o exotismo, fundado no instante do olhar imediato e embutido nesta estranheza que representa a condição de possibilidade da literatura. O primeiro exemplo é do personagem Guéque, do conto "Recado do morro" de João Guimarães Rosa, o bobo da Fazenda que tenta descrever para Pedro Orósio o perigo que ameaça a caravana do naturalista Alquist. São advertências de uma emboscada

5 "A busca de legitimaçấo do artista diante da ciência ou da filosofia se manifesta na afirmaçâo de seus direitos. $\mathrm{O}$ direito à inautenticidade, por exemplo, ou à transmutaçấo dos valores em geral. A legitimaçáo tem em perspectiva a posição do artista na sociedade. E o exotismo ocupa-se exatamente das posiçóes: começa inventando um indivíduo único e heterogêneo numa sociedade funcional, e, num mecanismo inverso e complementar, logo inventa uma sociedade 'artista' (o Japáo de Loti, ou o de Barthes) em que a única coisa heterogênea é o estranhamento da mirada que a expressa."

6 "Tornar-se chinês é tornar-se escritor." 
de sete homens que o menino Joãozezim ouve em recado do morro e conta para o bobo.

Representando por gestos cada verdade que o menino dizia: sungava as mãos à altura de um homem, ao ouvir do rei; e apontava para o morro, e mostrava sete dedos pelos sete homens, e alongava o braço por diante, para ser a espada, e formava cruz com dois dedos e beijava-a, ao nome de Deus; e batia caixa com as mãos na barriga, e com uma careta e um esconjuro figurava a aparição da Morte. Tudo, por seus meios, ele recapitulava, e pontuava cada estância com um feio meioguincho. Mas Pedro Orósio, que via e ouvia e não entendia, achava-lhe muita graça (GUIMARÂES ROSA, 2007, p. 27).

No conto, as personagens mais ligadas à paisagem e à natureza da região expressam sua sabedoria em descriçóes que o viajante Alquist não entende em nenhuma língua. Nem o guia local Pedro Orósio percebe esse sentido urgente antes de tirar as botas e pisar descalço na terra de seu caminho. Nesse instante Pedro Orósio percebe o que o menino Joãozezim ouvia e o que Guéque olhava.

Também aqui a estranheza do exótico se revela na língua materna, não como dialeto nem em função de uma semântica diversa. O problema para os personagens do conto de Guimarães Rosa é não perceber a diferença entre o ver e o dizer, de modo que Pedro Orósio não reconhece na visão o que ouve e não entende nas palavras o que não vê. Para o exotista tradicional, a finalidade banal é reconhecer no final da viagem o que já esperava e o que já sabia. Para os viajantes de Guimarães Rosa o encontro não se realiza com algo que já se conhece, pelo contrário, descobre-se algo radicalmente surpreendente, que só se revela como um novo saber através de uma língua nova.

Se Guimarães Rosa dá o exemplo literário de um escritor crítico e estudioso comparável a Victor Segalen, César Aira encontra em Mario de Andrade um escritor com a liberdade de um Pierre Loti:

Tomemos uno de nuestros libros sagrados, cuyo nombre no podamos pronunciar sino de rodillas: Macunaima. También aquí la superficie reina, la inmensa desjerarquización de lo pertinente y lo insignificante, la risa que desorganiza los saberes, el capricho estético. Se diría un Loti en Brasil, pero un Loti soñado por Roussel, pues el reconocimiento ha sido suplantado por la invención plena (AIRA, 1993, p. 78). ${ }^{7}$

7 "Tomemos um dos nossos livros sagrados, cujo título só podemos pronunciar de joelhos: Macunaíma. Também aqui reina a superfície, a imensa desierarquização do pertinente e do insignificante, o riso que desorganiza os saberes, o capricho estético. Pode-se dizer que é um Loti no Brasil, mas um Loti sonhado por Roussel, porque o reconhecimento foi suplantado pela invenção plena." 
É francamente comovente observar o respeito enorme e inédito do escritor argentino pela literatura brasileira. ${ }^{8}$ Aira reconhece na recriação de Mário de Andrade dos testemunhos de viajantes europeus na Região Amazônica do século 19, e em sua posterior composição poética e rapsódica, o documento do encontro do brasileiro ou do latino-americano consigo mesmo em função do exotismo. Não o exotismo no estranho lá fora, pelo contrário, na estranheza do miolo íntimo da identidade própria sempre fora de alcance.

Mientras que Mário hizo de su obra una máquina para volverse brasileño. Es cierto que él ya era brasileńo, pero eso es lo que la modernidad ha puesto en la contingencia y el azar, para hacer inteligible este dato, el brasileño debe hacer además "como si..." fuera brasileño. Y no hay otro medio para serlo en la realidad. Los absolutos del pensamiento se tiñen de ficción para entrar a la vida. Y esta es la definición última con la que yo trabajo: la literatura es el medio por el que un brasileño se hace brasileño, un argentino argentino. Es lo necesario para que el Brasil se transforme en el Brasil, para que la Argentina llegue a ser la Argentina. En última instancia, para que el mundo se transforme en mundo.

Y no hablo de llegar a ser un brasileño o un argentino de verdad, genuino. La autenticidad no es un valor que esté dado de antemano, esperando al individuo que lo ocupe. Por el contrario, es una construcción como lo es el destino, o el estilo. No se trata solo de ser argentino o brasileńo, sino de inventar el dispositivo por el que valga la pena serlo, y vivir una vida siéndolo (AIRA, 1993, p. 79). ${ }^{9}$

8 Ver também Aira, 1986, p. 24-25.

9 "Enquanto Mário fez de sua obra uma máquina para se tornar brasileiro. Decerto ele já era brasileiro, mas é isso que a modernidade pôs na contingência e no acaso, para tornar inteligível este dado, o brasileiro deve, além do mais, fazer 'como se...' fosse brasileiro. E não há outro meio para sê-lo, na realidade. Os absolutos do pensamento se tingem de ficção para entrar na vida. Esta é a definição última com que eu trabalho: a literatura é o meio pelo qual um brasileiro se torna brasileiro, um argentino, argentino. É aquilo que é necessário para que o Brasil se transforme no Brasil, para que a Argentina chegue a ser a Argentina. Em última instância, para que o mundo se transforme em mundo.

"E não falo de chegar a ser um brasileiro ou um argentino de verdade, genuíno. A autenticidade não é um valor que esteja dado de antemão, à espera de que o indivíduo o ocupe. Pelo contrário, é uma construçấo, como o é o destino, ou o estilo. Não se trata só de ser argentino ou brasileiro, mas de inventar o dispositivo pelo qual valha a pena sê-lo, e viver uma vida sendo-o." 


\section{Referências}

AIRA, César. "Desdeñosa ignorancia por la literatura del Brasil.” Creación. La Revista Argentina para el Nuevo Siglo, ano 1, n. 3, Buenos Aires, 1986.

AIRA, César. "Exotismo." Boletin/3 del Grupo de Estudios de Teoria Literaria, n. 3, Rosário, 1993.

AIRA, César. Nouvelles impressions du Petit Maroc. Tradução de Joca Wolff. Florianópolis: Cultura e Barbárie, 2011.

AIRA, César. "Raymond Roussel. La clave unificada.” Evasión y otros ensayos. Buenos Aires: Literatura Random House, 2018.

AIRA, César. Un episodio en la vida del pintor viajero. Rosário: Beatriz Viterbo, 2020.

GOYTISOLO, Juan. Paisajes después de la batalla. Madri: Galaxia Gutenberg, 1998.

SEGALEN, Victor. Essai Sur l'Exotisme Une Esthétique du Divers. Paris: Fata Morgana, 1978.

SEGALEN, Victor. Essay on Exoticism: An Aesthetics of Diversity. Durham: Duke University Press, 2002.

Karl Erik Schøllhammer é Professor Titular do Departamento de Letras da PUCRio. Pesquisador com bolsa de produtividade do CNPq e Cientista do Nosso Estado da Faperj (2007-2009/2013-2016/2016-2019). É autor, co-autor e editor de vários livros, entre eles: Literatura e Realidade(s) (2010), Atrocity Exhibition (2011), Memórias do Presente (2012), Criatividade sem Limite? (2012), Cenários Contemporâneos da Escrita (2013), Literatura e artes na critica contemporânea (2016) e Linguagens visuais: literatura, artes, cultura (2018). De autoria integral, os títulos mais recentes são Além do visivel — o olhar da literatura (2007, 2016), Ficção brasileira contemporânea (2009, 2011) e Cena do Crime (2013).

E-mail: karlerikschollhammer@me.com 